\title{
Changes in Demineralized Enamel around Brackets Detected by Laser Fluorescence Following Fluoride Treatment
}

\author{
Jose Francisco Gomez-Clavel ${ }^{1 *}$, Delia Arroyo-Chimalpopoca ${ }^{2}$ and Alejandra Parra-de la Merced ${ }^{2}$ \\ ${ }^{1}$ Laboratory for Research in Education and Dentistry, FES-Iztacala, National Autonomous University of Mexico, Mexico \\ ${ }^{2}$ Specialization in Orthodontics, FES-Iztacala, National Autonomous University of Mexico, Mexico
}

*Corresponding author: Jose Francisco Gomez-Clavel, FES-Iztacala, National Autonomous University of Mexico, Avenida de los Barrios 1 Los Reyes Iztacala, 54090 Tlalnepantla, Mexico, Tel: +52 5556231161; E-mail: gomclave@gmail.com

Rec Date: Feb 26, 2015; Acc Date: Mar 10, 2015; Pub Date: Mar 14, 2015

Copyright: (c) 2015 Gomez-Clavel JF, et al., This is an open-access article distributed under the terms of the Creative Commons Attribution License, which permits unrestricted use, distribution, and reproduction in any medium, provided the original author and source are credited.

\begin{abstract}
Objective: To evaluate in-vitro, using red laser-light induced fluorescence (LF), the effect of three fluoride compounds on the demineralization-remineralization process around brackets bonded with glass ionomer cement (GIC) or resin-based cement.

Materials and method: The material comprised a sample of 60 premolars. 30 brackets were bonded with resin and 30 with glass ionomer cement. The enamel around the bracket was exposed to three demineralizationremineralization cycles to create a white spot lesion. After each cycle a fluorescent dye was applied to the enamel to measure laser fluorescence using a DIAGNOdent LF2190. The lesions were remineralized with three different commercial products: $12,000 \mathrm{ppm}$ fluoride, $1,500 \mathrm{ppm}$ fluoride, and $900 \mathrm{ppm}$ fluoride. After pH cycles, the tooth received three weekly fluoride treatments and LF measurements with the dye were taken.
\end{abstract}

Results: The initial LF values of the enamel around resin-bonded $(2.0 \pm 0.94)$ or GIC-bonded brackets $(1.86 \pm$ $0.62)$ showed no differences ( $p>0.05)$. After $\mathrm{pH}$ cycling, LF values showed no difference between the groups. The LF mean was $15.15 \pm 4.28$. The three fluoride compounds produced enamel remineralization around the brackets. Following fluoride treatment, a score was created based on the difference between LF post fluoride treatment and the initial LF values. These LF values showed statistical differences $(p<0.001)$. Treatment with $900 \mathrm{ppm}$ fluoride produced the highest remineralization values in both the resin and the GIC group.

Conclusion: The three fluoride compounds tested had the ability to remineralize enamel lesions produced by $\mathrm{pH}$ cycling around brackets bonded with resin or GIC.

Keywords: Dental caries; White spot lesion; Laser fluorescence; Orthodontic brackets; Orthodontic cements

\section{Abbreviations:}

LF: Red Laser-light Induced Fluorescence; GIC: Glass Ionomer Cement; WSL: White Spot Lesion; TMPyP: Tetrakis N-methylpyridyl Porphyrin

\section{Introduction}

Dental caries is the result of an imbalance between the demineralization and remineralization of dental structures, a process that is influenced by factors that lead to demineralization, such as poor nutritional habits, and by protective factors, such as exposure to fluoride [1]. Clinically decalcified enamel appears as an opaque white spot lesion (WSL) and represents the initial stage of caries formation [2]. Over time, the WSL may be recalcified; however, the opaque color usually remains and can appear as a stain, making it even less esthetic. Enamel demineralization is a common sequela of orthodontic treatment when oral hygiene is poor. WSLs are attributed to prolonged plaque accumulation around the brackets. Incipient caries form as early as four weeks after the placement of fixed orthodontic appliances, although the formation of established caries lesions usually takes at least six months. WSLs are one of the most prevalent side effects of fixed orthodontic treatments and affect about $50 \%$ of patients [3].

It is well established that fluoride increases the initial rate of remineralization of early enamel lesions and then slows down the caries process, and also that it is the most important agent in caries prevention [4]. Self-applied methods of fluoride delivery have been recommended for WSL prevention. Regular use of fluoridated toothpastes have proved unsuccessful in preventing lesions during fixed orthodontic treatment [5]. Fluoride mouthwashes have an excellent risk-benefit ratio [6], but there is no conclusive evidence as to their benefits in preventing WSL demineralization during orthodontic treatment [7]. Some topical fluoride products in the form of varnishes, solutions or gels have been used too with limited results and there is a lack of reliable evidence as to their effectiveness for remineralizing post orthodontic WSL [8]. Demineralization and remineralization processes leading to caries activity in which the first visible sign is the white spot can be detected and quantified using various fluorescencebased optical methods for detecting the earliest signs of enamel demineralization. This therefore affords the opportunity to intervene with aggressive therapies (mainly fluorides) at an early stage, arrest the lesion, encourage remineralization, and avoid the need for restorative intervention [9]. A laser-based fluorescence device, the DIAGNOdent, 
was introduced to detect and monitor the progression of caries lesions. The device generates a laser beam that penetrates the tooth surface and is absorbed by the surrounding tooth material. Carious tissue emits stronger fluorescence than sound tissue does in the red and infrared part of the spectrum $(\lambda=655 \mathrm{~nm})$ [10]; hence, fluorescence from a carious region is greater than that from sound tissue. The origin of fluorescence in carious tissue lies in oral bacterial porphyrins. Porphyrins are produced by several types of oral bacteria and can be extracted from the caries lesion. Carious material had maximum fluorescence intensity in the red spectral region, and contained mainly protoporphyrin and mesoporphyrin. Artificial carious lesions have no bacteria or their metabolites, nor do they produce a significant increase in fluorescence compared to sound surfaces [11]. The use of fluorescent dyes was proposed in order to improve the detection rate of early caries lesions [12]. The association with tetrakis Nmethylpyridylporphyrin (TMPyP) showed promising results in detecting and quantifying early caries lesions on smooth surfaces around brackets [13].

The aim of the study was to evaluate in-vitro the effect of three fluoride compounds on white spot lesions by using red laser-light induced fluorescence to measure the amount of protoporphyrin absorbed in enamel treated by demineralization-remineralization $\mathrm{pH}$ cycling around brackets bonded with glass ionomer cement (GIC) or resin-based cement.

\section{Materials and Methods}

\section{Teeth}

Written informed consent was obtained from the patients to use their teeth in our study. Sixty recently extracted non-carious human premolars, for mainly orthodontics reasons, were placed in distilled water at room temperature with thymol crystals added to inhibit bacterial growth.

The teeth were visually sound; those with stains, calculus, or hypomineralization were excluded from the study. All were rinsed thoroughly under tap water and carefully cleaned with a toothbrush.

\section{Treatment of the teeth for the demineralization- remineralization process}

Each tooth was sectioned and the root discarded. The area occupied by the bracket plus a $3-\mathrm{mm}$ margin were covered with adhesive tape and the remainder of the tooth was etched and covered with resin sealant (Heliosit ${ }^{\oplus} \mathrm{F}$, Ivoclar). 30 brackets were bonded with resin (Heliosit $^{\circ}$ Orthodontic, Ivoclar) and 30 with glass ionomer cement (GC Fuji ORTHO ${ }^{\mathrm{ma}} \mathrm{LC}$ ). The non-covered area of enamel was exposed to three cycles of demineralization-remineralization to create a white spot lesion [14].

Demineralization solution: $1.5 \mathrm{mMCaCl}_{2}, 0.9 \mathrm{mM} \mathrm{KH} \mathrm{KO}_{4}, 150$ $\mathrm{mMKCl}, 0.1 \mathrm{M}$ sodium acetate buffer, and $30 \mathrm{mM}$ acetate in hydroxyethtyl cellulose. The $\mathrm{pH}$ was adjusted to 4.7 and controlled before and after each 3-day cycle.

Remineralization solutions: $1.5 \mathrm{mMCaCl}_{2}, 0.9 \mathrm{mM} \mathrm{KH}_{2} \mathrm{PO}_{4}$, and $150 \mathrm{mMKCl}$ at $\mathrm{pH} 7.0$, again controlled before and after each 3-day cycle.

Each cycle was scheduled for 3 days and was repeated 6 times for a total experimental period of $\mathrm{pH}$ cycling of 18 days.

\section{DIAGNOdent}

After each cycle, $10 \mu \mathrm{l}$ of a solution of $0.2 \mathrm{mM}$ of a fluorescent dye [tetrakis(N-methylpyridyl)porphyrin (TMPyP)] (Aldrich, Milwaukee, USA) dissolved in dimethyl sulfoxide was applied to the enamel for one minute; the crown of the tooth was dipped in distilled water (two minutes, slowly stirred with a magnetic stirrer) and dried with an air syringe for 5 seconds. Laser fluorescence measurements were taken with a DIAGNOdent LF2190, (KaVo, Biberach, Germany) and using a flat-tip probe recommended for smooth surfaces. The measurement time was standardized to around $10 \mathrm{~s}$. As recommended by the manufacturer, the instrument was calibrated against its own supplied ceramic standard before every measurement.

\section{Treatment Groups}

The setup of the experiment is presented in Table 1. The lesions surrounding the bracket bases were remineralized with three different commercial products: 12,000 ppm fluoride (Oral-B Minute-Gel, Procter and Gamble), 1500 ppm fluoride (Fluoxytil gel, GlaxoSmithKline), and $900 \mathrm{ppm}$ fluoride (MI Paste plus, GC America). After the $\mathrm{pH}$ cycles, the tooth was dipped in deionized water for two minutes and the lesion dried. The fluoride compound was then applied to the lesion around the bracket for three minutes. This was subsequently washed and dried before adding the TMPyP. Laser fluorescence measurements were then taken. The tooth was placed in artificial saliva $\left(20 \mathrm{mmol} \mathrm{Na} \mathrm{HCO}_{3}, 3 \mathrm{mmol} \mathrm{NaHPO}_{3}, 1 \mathrm{mmol} \mathrm{CaCl}_{2}\right.$, $\mathrm{pH}$ 7.0) for one week and the same procedure was then repeated at 7 and 14 days.

\section{Statistical Analysis}

Since the purpose of the study was to determine the differences in remineralization in the enamel around braces bonded with resin and that around braces bonded with GIC in three different fluoride treatments using red laser-light induced fluorescence, a score was created based on the difference between LF post fluoride treatment and the initial LF values. Two-way ANOVA with two-factor variables was used to determine whether there were significant differences between the three treatments. The Tukey HSD test was used to compare the group means $(\mathrm{p}<0.05)$.

\section{Results}

The LF values of the enamel around resin-bonded $(2.0 \pm 0.94)$ or GIC-bonded brackets $(1.86 \pm 0.62)$ showed no initial differences (p>0.05) (Table 1).

\begin{tabular}{|l|l|l|l|}
\hline Group & N & Mean & S.D. \\
\hline Resin-bonded brackets & 30 & 2 & 0.95 \\
\hline GIC-bonded brackets & 30 & 1.87 & 0.62 \\
\hline
\end{tabular}

Table 1: Initial laser fluorescence values of enamel around brackets bonded with resin o GIC and TMPyP

The demineralization-remineralization process is not affected by the bonding material. There are no differences between the LF values of the enamel surface around resin-bonded brackets after $\mathrm{pH}$ cycling $(16.43 \pm 3.6)$ and those around GIC-bonded brackets $(13.86 \pm 4.58)$ ( $>0.05)$ (Table 2). 


\begin{tabular}{|l|l|l|l|}
\hline Group & N & Mean & S.D. \\
\hline Resin-bonded brackets & 30 & 16.43 & 3.61 \\
\hline GIC-bonded brackets & 30 & 13.87 & 4.58 \\
\hline
\end{tabular}

Table 2: Laser fluorescence values of enamel around brackets bonded with resin or GIC after three demineralization-remineralization cycles and TMPyP $(\mathrm{p}>0.05)$

\section{Remineralization induced by fluoride compounds}

After application of fluoride treatments, the three compounds produced remineralization of enamel around brackets (measured as the lowest LF values) (Table 3).

\begin{tabular}{|l|l|l|l|}
\hline Groups & N & Mean & S.D. \\
\hline Resin-bonded bracket (12,000 ppm fluoride) & 10 & 5.9 & 1.10 \\
\hline Resin-bonded bracket (1,500 ppm fluoride) & 10 & 7.7 & 2.21 \\
\hline Resin-bonded bracket (900 ppm fluoride) & 10 & 3.5 & 1.18 \\
\hline GIC-bonded bracket (12,000 ppm fluoride) & 10 & 4.9 & 1.72 \\
\hline GIC-bonded bracket (1,500 ppm fluoride) & 10 & 6.6 & 1.95 \\
\hline GIC-bonded bracket (900 ppm fluoride) & 10 & 4.5 & 0.70 \\
\hline Total & 60 & 5.5167 & 2.05 \\
\hline
\end{tabular}

Table 3: Laser fluorescence values of enamel around brackets bonded with resin or GIC after treatment with three weekly fluoride treatments and TMPyP

The scores for the difference between the LF values after three weekly fluoride treatments and the initial values shows that all fluoride treatments produce remineralization values near the enamel's initial LF values.

\begin{tabular}{|l|l|l|l|}
\hline Groups & N & Mean & S.D. \\
\hline Resin-bonded bracket (12,000 ppm fluoride) & 10 & 3.4 & 1.17 \\
\hline Resin-bonded bracket (1,500 ppm fluoride) & 10 & $5.9^{*}$ & 2.08 \\
\hline Resin-bonded bracket (900 ppm fluoride) & 10 & $2^{*}$ & 1.05 \\
\hline GIC-bonded bracket (12,000 ppm fluoride) & 10 & 3.4 & 2.01 \\
\hline GIC-bonded bracket (1,500 ppm fluoride) & 10 & $3.9^{*}$ & 1.45 \\
\hline GIC-bonded bracket (900 ppm fluoride) & 10 & $2.6^{*}$ & 0.97 \\
\hline Total & 60 & 3.4 & 1.455 \\
\hline
\end{tabular}

${ }^{*}$ Significant differences ANOVA $p>0.001$

Table 4: Difference between the LF values of enamel around brackets after three weekly fluoride treatments and TMPyP and the initial LF values of the enamel

The score indicates that the best mineralization rates were produced by $900 \mathrm{ppm}$ fluoride (mean 2,3), average rates by $12,00 \mathrm{ppm}$ fluoride (3.3), and the greatest difference by $1,500 \mathrm{ppm}$ fluoride $(5,5)$.
The Tukey HSD test showed statistically significant differences in the remineralization rate of the groups treated with $900 \mathrm{ppm}$ fluoride gel $(\mathrm{p}<0.001)$ (Table 4).

Treatment with $900 \mathrm{ppm}$ fluoride produces the highest remineralization values in both the resin and the GIC group.

\section{Discussion}

White spot lesions around the fixed appliance are an undesirable consequence of orthodontic treatment and can be attributed to the patient's lack of commitment to achieving proper plaque removal. Dentists face this problem during and after treatment and therefore should use all available strategies to intervene both at the beginning of and during the treatment, and after debonding.

Demineralization caused by bacterial metabolism removes Ca ions and $\mathrm{PO}_{4}$ from the hydroxyapatite crystals that make up the enamel rods, thereby creating a porous structure that allows the entry of water and, if desired, air, when the enamel surface is dried off with a triple syringe [15]. The demineralization is repaired by the precipitation of $\mathrm{Ca}$ and $\mathrm{PO}_{4}$ ions dissolved in saliva, which can be enhanced by the use of fluorides [2].

This study was performed for the purpose of determining which treatment method is most successful in treating in-vitro the demineralized white spot lesions that occur in the area adjacent to orthodontic brackets, which was done by assessing the laser fluorescence of enamel lesions with protoporphyrins.

Laser fluorescence (measured using a DIAGNOdent) has been used to determine the depth of caries lesions and, in conjunction with the caries risk assessment, define the type of treatment that these lesions require [16].

The laser fluorescence (LF) device in question allows for a quantitative method based on the emission of light from a diode laser and the measurement of the fluorescence emitted primarily from the carious tissues [10]. In clinical practice, the DIAGNOdent measures bacterial presence in the porous structure of demineralized enamel; therefore, in an in-vitro study such as ours, we need to incorporate the molecules present in bacteria before we can measure the laser fluorescence of enamel that has suffered acid attack in-vitro.

The initial LF values of the enamel in the resin-bonded group were $2.0 \pm 0.94$ and in the group bonded with GIC $1.86 \pm 0.62$, which correspond to the values for sound enamel reported $[17,18]$.

In an in-vitro study [13], laser fluorescence enhanced by fluorescent dyes proved effective in detecting initial demineralization around the brackets. In this study, the porphyrin was dissolved in water and added to a lesion produced by submerging the enamel in an acetic acid solution with the $\mathrm{pH}$ adjusted to 4.8 for 16 days, without $\mathrm{pH}$ cycling. The enamel lesion obtained produced mean LF values of $10.3 \pm 11.8$. In our study, we used $\mathrm{pH}$ cycling to produce enamel lesions and laser fluorescence with the help of protoporphyrin IX dissolved in dimethyl sulfoxide to assess the processes of demineralization and remineralization. The values that we obtained after the $\mathrm{pH}$ cycling for the enamel lesions around brackets were higher $(15.15 \pm 4.2896)$. These higher LF values may be because the lesion produced by demineralizing gel in the $\mathrm{pH}$ cycling process produces a subsurface lesion, whereas using only one demineralizing solution causes erosion. We recommend that this demineralization process model be considered for future experiments. 
The LF values we obtained suggest that the lesion was confined to the outer $400 \mu \mathrm{m}$ of enamel [17]. In an in-vitro study [14] that used the same methodology of $\mathrm{pH}$ cycling, viewed under polarized light microscopy, the lesions produced had an average depth of $19.9 \mu \mathrm{m}$ in the surface region, $87.6 \mu \mathrm{m}$ in the body of the lesion, and $132 \mu \mathrm{m}$ in the translucent zone; hence, the lesion progressed a total of $230.5 \mu \mathrm{m}$ on average. These data match the fluorescence readings in our study and in previous reports.

Resin-modified glass ionomer cements have been studied to assess their preventive effect around orthodontic brackets. Both in-vitro and in-vivo studies have reported a reduction in the remineralization of surfaces on which appliances have been bonded using this kind of cement $[19,20]$. Two systematic reviews show some evidence that the use of a glass ionomer cement for bracket bonding reduces the prevalence and severity of white spots compared to composite resins $[21,22]$. In our study, although the average laser fluorescence lesion around brackets bonded with a glass ionomer was below the average of the lesions around the brackets cemented with resin, the difference was not statistically significant, probably because the fluoride released by the GIC was dissolved in the solutions we used to produce the lesion in the enamel.

A randomized controlled trial aimed at determining the efficacy of fluoride varnish in reverting white spot lesions after fixed orthodontic treatment [23] reported LF values of 17.66 with a DIAGNOdent pen on white spot lesions after bracket debonding, after application of fluoride varnish to $22,600 \mathrm{ppm}$, obtained values of 11.88 at the 3month follow-up visit. At the 6-month follow-up visit, LF values were $10.10 \pm 4.86$. The LF measurements we obtained with three different solutions applied three times over a three-week period showed a return to values that are within the range for sound enamel, though not a return to the initial LF values measured, which may indicate that more time is required for complete remineralization. The compounds we tested have different concentrations of the fluoride ion; $900 \mathrm{ppm}$ fluoride cream produced the best results but were not different from those obtained using 12,500 ppm gel. The $1500 \mathrm{ppm}$ fluoride solution also produced a reduction in LF values to within the range for sound enamel.

We must consider not only the concentration of fluoride ions that promote remineralization, but also the other components of the formulations that accompany the fluorides, which enable the remineralization process to be more effective. The 12,500 ppm fluoride formulation consists of sodium fluoride and hydrofluoric acid; 1500 ppm fluoride solution is made up of sodium monofluorophosphate, and the $900 \mathrm{ppm}$ fluoride cream formulation includes sodium fluoride and phosphoric acid. The best results were provided by the two acidic sodium fluoride solutions. Additionally in 900 ppm fluoride, phosphoproteins/phosphopeptides with clusters of acidic residues, interact with calcium andstabilize clusters of calcium and phosphate, it was shown by immunolocalizationthat CPP were present inside a remineralized enamel subsurface lesion, indicating that they can pass through the size and charge impediments to enter the lesion [24].

The final result of the three applications of fluoride solutions was a decrease in LF values. As reported in earlier remineralization studies, repeat applications of fluoride are necessary to ensure the maximum benefit $[25,26]$.

\section{Conclusions}

The data from the present study confirm the effects of fluoride remineralization on human enamel in terms of LF values. The three fluoride compounds tested had the ability to remineralize enamel lesions produced by $\mathrm{pH}$ cycling.Protoporphyrins are a valuable, indeed indispensable aid in detecting demineralization by LF in-vitro. Treatment with $900 \mathrm{ppm}$ fluoride produces the highest remineralization values in lesions around brackets bonded with resin or GIC.

\section{Competing Interests}

The researchers declare not have funding or conflict of interest with any commercial entity.

\section{Authors' Contributions}

JFGC designed the study, analyzed the data and draft the manuscript. DA and AP carried out all the laboratory procedures and draft the manuscript. All authors read and approved the final manuscript.

\section{Acknowledgements}

The authors would like to thank Dr. Jorge Gersenowies Rodriguez for valuable support in statistical analysis.

This work was supported by grant: UNAM. PAPIME PE209312.

\section{References}

1. Featherstone JD (2008) Dental caries: a dynamic disease process. Aust Dent J 53: 286-291.

2. Ogaard B (2008) White Spot Lesions During Orthodontic Treatment: Mechanisms and Fluoride Preventive Aspects. SeminOrthod 14: 183-193.

3. Gorelick L, Geiger AM, Gwinnett AJ (1982) Incidence of white spot formation after bonding and banding. Am J Orthod 81: 93-98.

4. Tufekci E, Dixon JS, Gunsolley JC, Lindauer SJ (2011) Prevalence of white spot lesions during orthodontic treatment with fixed appliances. Angle Orthod 81: 206-210.

5. Ten Cate JM (2013) Contemporary perspective on the use of fluoride products in caries prevention. Br Dent J 214: 161-167.

6. O'Reilly MM, Featherstone JD (1987) Demineralization and remineralization around orthodontic appliances: an in vivo study. Am J OrthodDentofacialOrthop 92: 33-40.

7. Benson PE, Shah AA, Millett DT, Dyer F, Parkin N, et al. (2005) Fluorides, orthodontics and demineralization: a systematic review. J Orthod 32: 102-114.

8. Kalha AS (2013) Lack of reliable evidence of the effectiveness of remineralising agents for the treatment of post orthodontic white spot lesions. Evid Based Dent 14: 76-77.

9. Pretty IA, Maupome G (2004) A closer look at diagnosis in clinical dental practice: part 5. Emerging technologies for caries detection and diagnosis. J Can Dent Assoc 70: 540.

10. Hibst R, Paulus R, Lussi A (2001) Detection of occlusal caries by laser fluorescence: basic and clinical investigations. Med Laser Appl 16: 205213.

11. Lussi A, Hibst R, Paulus R (2004) DIAGNOdent: an optical method for caries detection. J Dent Res 83 Spec No C: C80-83.

12. Mendes FM, de Oliveira E, Araujo de Faria DL, Nicolau J (2006) Ability of laser fluorescence device associated with fluorescent dyes in detecting and quantifying early smooth surface caries lesions. J Biomed Opt 11: 24007. 
Citation: Gomez-Clavel JF, Arroyo-Chimalpopoca D, Parra-de la Merced A (2015) Changes in Demineralized Enamel around Brackets Detected by Laser Fluorescence Following Fluoride Treatment. Dentistry 5: 290. doi:10.4172/2161-1122.1000290

Page 5 of 5

13. Alencar CJ, Braga MM, de Oliveira E, Nicolau J, Mendes FM (2009) Dyeenhanced laser fluorescence detection of caries lesions around brackets. Lasers Med Sci 24: 865-870.

14. Gangler P, Kremniczky T, Arnold WH (2009) In vitro effect of fluoride oral hygiene tablets on artificial caries lesion formation and remineralization in human enamel. BMC Oral Health 9: 25.

15. Kidd EA, Fejerskov O (2004) What constitutes dental caries? Histopathology of carious enamel and dentin related to the action of cariogenic biofilms. J Dent Res 83 Spec No C: C35-38.

16. Jenson L, Budenz AW, Featherstone JD, Ramos-Gomez FJ, Spolsky VW, et al. (2007) Clinical protocols for caries management by risk assessment. J Calif Dent Assoc 35: 714-723.

17. Shi XQ, Tranaeus S, Angmar-Månsson B (2001) Comparison of QLF and DIAGNOdent for quantification of smooth surface caries. Caries Res 35: 21-26.

18. Lussi A, Megert B, Longbottom C, Reich E, Francescut P (2001) Clinical performance of a laser fluorescence device for detection of occlusal caries lesions. Eur J Oral Sci 109: 14-19.

19. Shungin D, Olsson AI, Persson M (2010) Orthodontic treatment-related white spot lesions: a 14-year prospective quantitative follow-up, including bonding material assessment. Am J Orthod Dentofacial Orthop 138: 136.e1-136.e8.
20. Paschos E, Kleinschrodt T, Clementino-Luedemann T, Huth KC, Hickel R, et al. (2009) Effect of different bonding agents on prevention of enamel demineralization around orthodontic brackets. Am J Orthod Dentofacial Orthop 135: 603-612.

21. Benson PE, Parkin N, Millett DT, Dyer FE, Vine S, et al. (2004) Fluorides for the prevention of white spots on teeth during fixed brace treatment. Cochrane Database Syst Rev: CD003809.

22. Yengopal V, Mickenautsch S (2011) Caries-preventive effect of resinmodified glass-ionomer cement (RM-GIC) versus composite resin: a quantitative systematic review. Eur Arch Paediatr Dent 12: 5-14.

23. Du M, Cheng N, Tai B, Jiang H, Li J, et al. (2012) Randomized controlled trial on fluoride varnish application for treatment of white spot lesion after fixed orthodontic treatment. Clin Oral Investig 16: 463-468.

24. Cochrane NJ, Cai F, Huq NL, Burrow MF, Reynolds EC (2010) New approaches to enhanced remineralization of tooth enamel. J Dent Res 89: 1187-1197.

25. KNUTSON JW (1948) Sodium fluoride solutions; technic for application to the teeth. J Am Dent Assoc 36: 37-39.

26. Mellberg JR, Nicholson CR, Miller BG, Englander HR (1970) Acquisition of fluoride in vivo by enamel from repeated topical sodium fluoride applications in a fluoridated area: final report. J Dent Res 49: 1473-1477. 